\title{
La lectura del modelo y su realización: la tarea de Cézanne
}

\section{Reading and making of a model: Cézanne's task}

\author{
María Elena Muñoz \\ Universidad de Chile, Chile \\ malena2265@gmail.com
}

- Resumen - El presente texto es fruto de una investigación que tuvo como eje la pregunta por el modelo y que estuvo centrada en la revisión de la correspondencia y la pintura de Paul Cézanne. Si admitimos que el modelo es aquello que articula la relación entre arte y naturaleza, entre pintura y mundo sensible, entonces ¿cómo entendía este pionero de lo que aceptamos como modernidad pictórica esa relación? ¿Qué era para él el modelo? ¿Cuál era su papel en la producción de obra? Estas son algunas de las interrogantes que el presente trabajo busca responder a través de la revisión crítica de las obras y de las cartas del pintor desde la perspectiva anunciada, es decir, bajo el foco que destaca la relación arte y naturaleza.

Palabras clave: modelo, naturaleza, sensación, modulación, armonía.

- Abstract - The following text is the result of a research made upon the letters and the painting of Paul Cézanne oriented by the quest about de model. According to my preliminary thinking, the model is what articulates the relationship between art and nature, between painting and the sensible world. How this pioneer of modern painting understood that kind of relation? What was the model for him? What was the model's role in the production of the work? These are some of the questions that the present article will try to answer by revising his letters, paintings, motifs, and giving special attention to the way in which art and nature are woven in Cézanne's work. Keywords: Model, Nature, Sensation, Realization, Harmony. 


\section{INTRODUCCIÓN}

Lo que activó el presente estudio fue una frase que aparece en una carta enviada por Paul Cézanne a un joven pintor no identificado en 1896. La frase completa dice así: "La lectura del modelo y su realización son a veces cosas que tardan en llegar» (Cézanne 322). El enunciado alude a la relación entre el objeto pictórico y su referente visual, o, dicho de otro modo, a la relación entre el arte y su modelo. Sugiere, primero, que el modelo no es algo que se presenta simplemente ante sus ojos, por el contrario, es algo que precisa ser descifrado. Propone luego que ese algo necesita realizarse, construirse, todo lo cual exige una ardua labor cuyos frutos podrían, eventualmente, ni siquiera ser vistos por el propio autor. La afirmación cezanniana insinúa que el vínculo entre modelo y obra no ocurre de manera mecánica: la operación a realizar constituye una lenta y ardua tarea. Si a esto le añadimos una cuestión expresada reiteradamente por el pintor, cuando insiste en que lo que pinta son sus «sensaciones coloreadas» respecto del mundo (y no los objetos o el aspecto del mundo) lo que se desprende es que Cézanne entiende al modelo como algo que habita al mismo tiempo el mundo y la mente (esprit) del artista. Esto indica que su posición se distanciaba tanto de un naturalismo de tipo servil como de las posiciones simbolistas que abogaban por el abandono completo del referente sensible y que eran las que estaban imponiéndose crecientemente hacia el fin de siecle. Era en el contexto antimimético del simbolismo que se promovía la construcción organizada de una pintura "pura»: una pintura cuyo modelo no estaría en el mundo exterior, sino en el reino de lo no visible: el de los valores universales.

No obstante, la promoción de la obra cezanniana provino en principio desde la esfera simbolista, Cézanne defendió insistentemente una postura contraria: la necesidad de mantener una mirada siempre atenta al motivo, para recién ahí empezar a organizar lo que él denominaba sus sensaciones. La convicción cezanniana respecto del papel ejemplar de la naturaleza es una cuestión en la que insistió reiterada, o, mejor dicho, obstinadamente. Para él, no hay arte sin consideración a la naturaleza, no porque este imite a aquella, sino porque sin esa medición, sin ese correlato imprescindible (entre naturaleza y arte) no puede imaginarse ni producirse un arte que opere precisamente como «armonía paralela (a la naturaleza)», tal como refiere en una de sus más lúcidas afirmaciones (carta a Joachim Gasquet, 1897)ํ. El modelo para Cézanne no era simplemente el motivo, sino las sensaciones experimentadas ante él; eso era lo que debía pintarse. Sin modelo no hay representación posible.

La frase completa dice así: «El arte es una armonía paralela a la naturaleza. ¿Qué pensar de los imbéciles que dicen que el artista es siempre inferior a la naturaleza?»(Cézanne 329). 


\section{LA LECTURA DEL MODELO}

Me interesa aquí atender el modo en que las relaciones entre Cézanne y el mundo de las apariencias sensibles se traman, de qué manera su obra aprende la lección de la naturaleza. De ningún modo, el pintor se limitaba quietamente a presenciar la muda extensión de las apariencias: el estudio penetrante del motivo y de las sensaciones que en su contacto se despiertan lo previnieron de aquello. Como él mismo afirmara, el motivo / modelo no se escoge ni se registra solamente: precisa ser leído, requiere de una operación de desciframiento. Podría decirse que la lectura es la condición que posibilita la traducción del modelo al universo otro y pleno que es la tela. Leer el texto de la naturaleza, sin ánimo de someterse a ella o sobrepasarla, no surge del mudo permanecer entre las cosas o del posicionarse pasivamente frente a ellas, que es lo que ocurre cuando estamos, como decía Husserl, en «actitud natural» -esa actitud cotidiana que se define por el modo en que se percibe el «mundo natural», el mundo que está «ahí delante» donde las cosas y los seres animados existen en una copresencia y donde se asume que cosas y seres son tal como son dadas, como aparecen-. La actitud natural supone percibir el mundo como una suerte de continuo, como un horizonte indeterminado que captamos indiscriminadamente. Hacer la lectura de la naturaleza, como lo hace Cézanne, constituye un acto de aislar la mirada, de mirar discriminando, de interrupción de ese continuo. Esta primera operación implica de inmediato un desafío a la actitud natural.

Al desafiar esa actitud natural por medio de una suspensión, de una puesta entre paréntesis, es decir, de una epoché, la conciencia deviene acto, esto es, movimiento que va y viene del sujeto al mundo y del mundo al sujeto. Tanto el mundo como la conciencia cesan de comportarse como sustancias inmutables o fijas (como sucede mientras se permanece en la actitud natural), para pasar a experimentarse como términos que solo son posibles en la relación. Esta les otorga a ambos existencia. Así, puede pensarse que el propio acto de lectura es, en principio, un acto de suspensión. Lo que se lee queda extraído del continuo, del fluir espacio temporal, destacado de en medio de una suerte de horizonte informe, en virtud de un acto de suspensión, de puesta entre paréntesis de la actitud natural.

Leer la naturaleza, al modo que el maestro de Aix lo hace, significa percibirla de forma intencionada, dirigirse hacia ella. Frente al mundo dado, el artista fija su atención en algo, deslinda un campo de visión, se detiene en las relaciones que se dan en el interior de ese algo y repara en el modo en que operan sus dependencias internas. Este paso, la lectura, es para Cézanne imprescindible: es lo que posibilita las condiciones de la representación, es decir, lo que hace posible que tenga lugar la articulación de sentido de lo que sus ojos han visto.

Que la lectura del modelo implique necesariamente una mirada intencionada sobre el mundo, es una «evidencia» que aportan sus propios cuadros, como también su pensamiento expresado en la forma de cartas. No se propone registrar las cosas 
«tal como aparecen», puesto que no recibe al mundo como algo que esté simplemente ahí. La mirada intencionada de Cézanne determina una construcción visual que claramente se distancia de aquellas que podríamos imaginar animadas por el principio de imitación de lo visible. Cada uno de los cuadros de Cézanne representa un desafío a la actitud natural; son la puesta en obra de una intencionalidad dirigida al mundo.

\section{EL OJO, EL ESPÍRITU, LA EXPERIENCIA}

La lectura del modelo comienza entonces con una mirada intencionada por el ojo $y$, antes que eso, por el cuerpo. Esta lectura se inicia con una operación perceptual donde el propio cuerpo opera como órgano rector. Cuando el artista se involucra en la lectura del motivo se involucra todo él, con sus ojos, su cuerpo y su experiencia. Con su cuerpo el sujeto se ve implicado en lo que ve y en lo que conoce, esto es, en lo que representa. Pero la visión del pintor no solo registra y descifra sino que también agrega, proyecta y, solamente en este sentido, conoce. La visión del pintor, dice Merleau-Ponty en El ojo y el espíritu, no aprende sino viendo, no aprende sino de sí misma. El ojo ve el mundo y lo que le falta al mundo para ser cuadro y lo que le falta al cuadro para ser el mismo (21).

Sin embargo, esa intencionalidad que orienta la mirada de Cézanne no es inocente. No responde solamente a un acto corporal tramado con la conciencia actual del artista. Aunque el enfoque fenomenológico no lo considere, es preciso advertir una cuestión que en este caso es fundamental: la intencionalidad está motivada a su vez por la experiencia, una experiencia que hace que el cuerpo del pintor se ubique en un determinado lugar y en una determinada posición, que privilegie un motivo sobre otros muchos posibles, una cierta experiencia que lo hace mirar de una cierta manera. Suspender la actitud natural -si volvemos a Husserl-consiste en dejar entre paréntesis tanto los hábitos perceptuales como las convicciones sobre el mismo mundo. Pero en el caso de un pintor hay algo más: se trata igualmente de suspender las convenciones que pesan sobre la disciplina con la cual trabaja: la pintura. Cézanne no ensaya simplemente una mirada discriminadora para atender a la naturaleza como podría ejercerla cualquiera de nosotros. La suya es una mirada de pintor, una mirada informada por la historia de las obras de arte, por el museo, por las lecturas, por las charlas con otros artistas, por las circunstancias históricas, por sus vivencias, por su ánimo y, además de todo eso, por sus convicciones y sus metas como artista. Él lleva su cuerpo y con él su ojo educado al paisaje natural; allí se apresta a elaborar a partir de la lección que este puede darle, aunque, paradójicamente, se empeñe en verlo con los ojos de un primitivo. Cézanne quiso practicar una clase de suspensión al intentar poner entre paréntesis los preceptos que alguna vez orientaron a los viejos maestros, en un sentido más general, la lección del museo. Ese ánimo es el que expresa a Émile Bernard en una carta de octubre de 1905: la tesis a desarrollar consiste -sea cual sea nuestro temperamento o forma de potencia en presencia de la 
naturaleza- en plasmar la imagen de lo que vemos olvidando todo lo que apareció antes de nosotros (el subrayado es mío), lo cual, creo yo, debe permitir al artista plasmar toda su personalidad, grande o pequeña (Cézanne 390)².

Es difícil admitir, sin embargo, que Cézanne quisiera olvidar todo lo aprendido, teniendo en consideración el reconocimiento que en otras ocasiones brinda al arte del pasado, cuestión que no solo se revela en sus cartas sino fundamentalmente en la enorme cantidad de dibujos y estudios que dejó a partir de la obra de los artistas de otro tiempo. Fueron varios los maestros de los cuales extrajo valiosas lecciones, y sus visitas al museo eran una actividad frecuente de aprendizaje sistemático. Las vivencias de Cézanne no comenzaron en el momento en que se puso frente al referente natural; la experiencia que pone al servicio de la lectura del modelo venía elaborándose desde su encuentro con el paisaje de su infancia y, sobre todo, a partir de su encuentro con el propio arte: aquel que vio, aquel que leyó. Insistió mucho en la necesidad de enfrentar el paisaje con los ojos de un primitivo. Ser "primitivo» era algo que perseguía porque justamente sentía que no lo era: ser un "primitivo» no era algo espontáneo, natural. Esa capacidad de ver «lo que le falta al mundo para ser cuadro» (Merleau-Ponty) se la debía a su ojo entrenado de tanto observar a los viejos y nuevos maestros, reales o no: en su memoria estaban Delacroix, Tintoretto, Tiziano, Rubens y Poussin, pero sobre todo estaba Frenhofer, el pintor imaginado por Balzac en aquella pequeña novela que narra los denodados esfuerzos del artista verdadero y que Cézanne atesoró y releyó muchas veces. Confesó que no dejó ningún día de ir al Louvre mientras estuvo en París en su juventud, donde copió algunos cuadros de Poussin, el pintor que, en tanto personaje, se había asomado en su contacto con Frenhofer a los abismos de la creación pictórica. La percepción, mal que mal, no sorprende a las cosas ni a los hombres fuera de la experiencia; la práctica de la pintura y los desafíos de la realización predispusieron la mirada que Cézanne extendió sobre la naturaleza que se empeñó en leer ${ }^{3}$ :

La necesidad que Ud. siente de encontrar un punto de apoyo moral e intelectual en obras que estoy seguro nunca se superarán, le pone sobre aviso constantemente acerca de la investigación incesante de los medios entrevistos que le conducirán seguramente a sentir ante la naturaleza sus propios medios de expresión; y el día en que Ud. los posea, esté convencido de que encontrará sin esfuerzo y ante la naturaleza, los medios empleados por los cuatro o cinco grandes de Venecia (Cézanne 231).

2 Su «tesis» se asemeja bastante al modo en que Mallarmé se refería a la pintura de Manet o, mejor dicho, a las concepciones de Manet sobre la pintura. "Cada obra debe ser una nueva creación de la mente. La mano, es cierto, conservará algunos de sus secretos de manipulación adquiridos, pero el ojo debe olvidar todo lo demás que haya visto (el subrayado es mío) y aprender de nuevo la lección que hay ante él. Debe abstraerse de la memoria, viendo solo aquello que mira, y eso como por primera vez» (cit. en Solana 96). Esto que destaca Mallarmé, es decir, la necesidad de olvidar, de ver todo como si fuese la primera vez, es una convicción convertida en credo por los artistas que años más tarde se afiliarán al simbolismo pictórico y que serán los encargados de definir a Cézanne como el «primitivo de un nuevo arte».

3 Además de eso, habría que considerar su interés por la literatura; en su juventud, Virgilio, a quien leía en latín, y en su madurez, Balzac, Flaubert, Stendhal y Baudelaire, por nombrar a sus preferidos. 
Esta fundamental experiencia fue la que orientó su intencionalidad al enfrentar el motivo. Solo luego de acopiada esta reserva, dirigió su mirada al paisaje; solo luego se convirtió en el gran maestro que lo conminaba a transformar sus confusas sensaciones en una organización nueva y totalmente plena. En su obra de madurez Cézanne logró situarse en una zona equívoca y tensa, intentando conciliar la tradición clásica con el modus operandi de unos artistas (los impresionistas) que pretendían, o se cree que pretendían, ponerla en crisis, pero sobre todo trabajando en el intersticio donde se encuentran la naturaleza externa y la mente del artista, donde se conecta el mundo y la pintura. Más bien habría que suponer que, en lugar de ignorar a los viejos maestros, lo que intenta es dejarlos en un fondo; la mirada sobre el natural se vuelve protagónica, mientras el foco de intención está en el modelo natural. Presumo que lo que Cézanne intenta expresar es que, mientras se está frente al modelo natural, la prioridad la constituye la experiencia que ha de entablarse entre el mundo natural y el artista, ya que, como se verá más adelante, lo que Cézanne intenta pintar no es el paisaje -el motivo ante sus ojos-, sino aquello que se produce en su contacto, es decir, sus sensaciones.

El encuentro con el motivo ${ }^{4}$ genera en el artista un tipo de respuesta que se puede describir como pensamiento visual: una percepción del mundo que no está escindida de la operación inteligible; un proceso de pensamiento no desligado que opera en la percepción. Cézanne piensa la pintura como elaboración activa de una relación: asume que la naturaleza «de afuera» y su propia conciencia visual deben estar implicadas, tramadas como un tejido muy fino y apretado del cual nada puede escaparse. Por lo mismo, ya a partir de esta primera fase, que es la lectura, se sigue que el paso siguiente de aquella no es -no puede ser- la simple mímesis mecánica, el remedo, sino más bien una operación tendiente a la instalación de una nueva región de lo visible, ofrecida por la integración del propio artista a la trama del mundo. La pintura, el cuadro finalmente, deviene producción de algo que se genera como fruto de la operación vinculante entre arte y naturaleza, es decir, de una mímesis activa. «El Louvre es el libro en que aprendemos a leer. Sin embargo, no debemos contentarnos con retener las bellas fórmulas de nuestros ilustres predecesores. Salgamos de él para estudiar la hermosa naturaleza, tratemos de extraer el espíritu de esta e intentemos expresarnos según nuestro temperamento personal» (Cézanne 389).

El motivo no debe copiarse «tal y cual» se presenta a la mirada del pintor, sino que debe ser transformado en un todo armónico por medio de su observación aguda y de las sensaciones que este provoca en el artista. Este todo armónico no se logra aplicando criterios preestablecidos, sino por el estudio del motivo y articulando, en la práctica, una lógica de la representación.

Es necesario salir a estudiar la naturaleza, pero, cuando se es pintor, la naturaleza no se puede abordar sino a expensas de un entrenamiento previo. Cézanne

\footnotetext{
Por ahora estoy usando el término motivo (motif) cezanniano, en lugar de modelo. En los próximos
} apartados será precisada la diferencia entre ambos. 
puso su conocimiento, su pensamiento visual, el museo y las ideas en contacto con el mundo natural, pero es preciso insistir en que su objetivo no era imponer sobre el paisaje unos criterios organizativos adquiridos: lo que perseguía era que esas ideas y que ese conocimiento se pusieran a actuar en el contacto con lo natural, que la potencia de la pintura surgiera del encuentro con la naturaleza y no antes, como consecuencia directa de un modelo de organización. No se trataba de concebir con antelación, de seguir un programa de antemano definido. Su trabajo no pierde de vista el fenómeno ante sus ojos, no porque quiera transferir lo visible a la tela sin más, sino porque el pintor necesita estar compenetrado con aquello que ve y, en un sentido más amplio, con lo visible de lo cual también es parte.

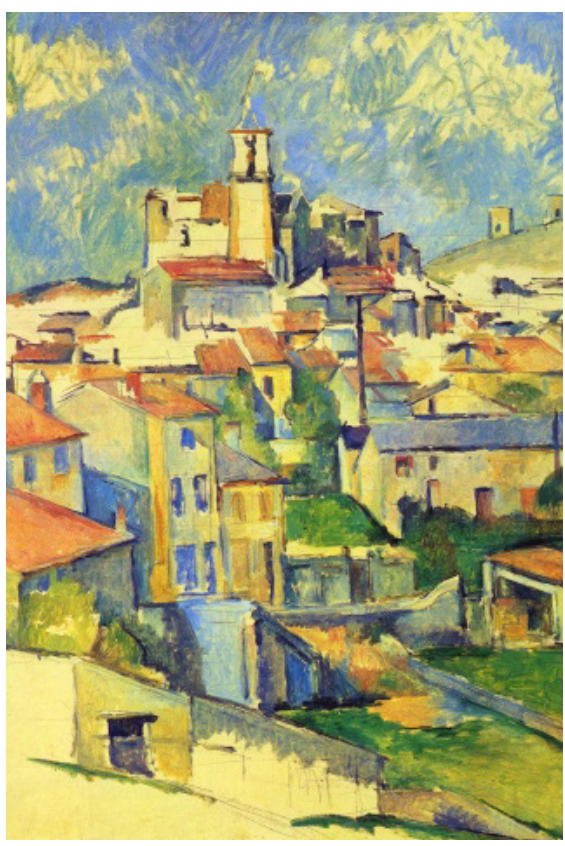

Figura 1. Paul Cézanne

Gardanne, 1885-86.

Óleo sobre tela, $92 \times 74,5 \mathrm{~cm}$.

The Brooklyn Museum of Art

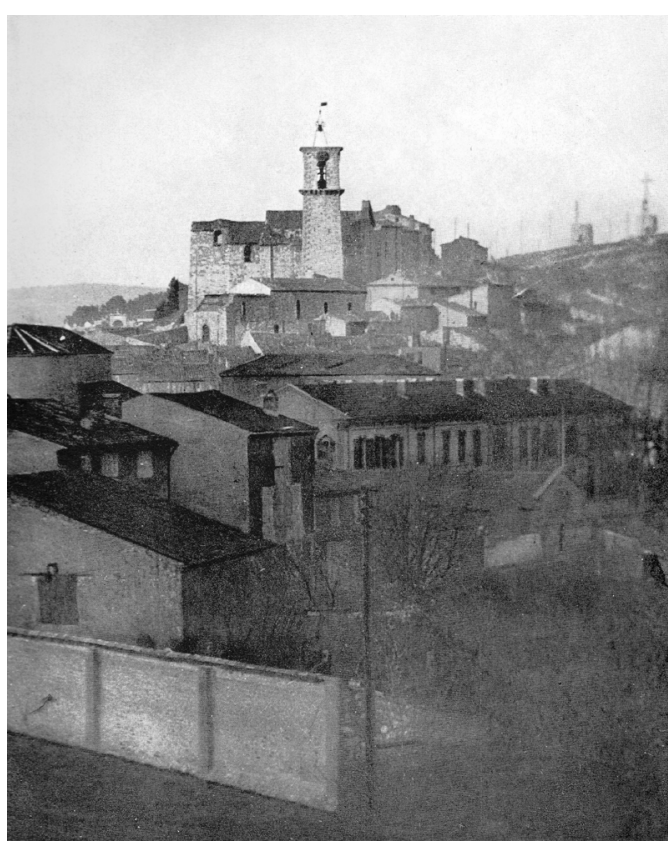

Figura 1-A. Erle Loran

Fotografía del motivo 1927

Véase, por ejemplo, la Figura 1. Representa una vista de Gardanne, un pueblo montañoso cercano a Aix-en-Provence. El formato vertical, poco común en cuadros de paisaje, probablemente fue escogido para enfatizar la disposición ascendente de las casas y demás construcciones. El cuadro pareciera no estar terminado, ya que se dejan ver varios espacios de la tela sin cubrir con óleo. Se pueden observar también trazos del dibujo de fondo. La ejecución se revela de algún modo «torpe», poco «académica»y, por cierto, nada de «naturalista». Sin necesidad de avanzar más en la descripción del cuadro, es posible reconocer desde ya que Cézanne no estaba tomando su «motivo» - una cierta vista de un villorrio del sur de Francia-como un 
simple dato ante sus ojos, sino como un estímulo sensible que necesita organizar y a partir del cual precisa tomar ciertas decisiones.

Comparando el cuadro con la fotografía del motivo, tomada por Erle Loran ${ }^{5}$ a comienzos del siglo pasado, se puede apreciar, por ejemplo, que Cézanne exaltó la verticalidad estrechando el formato y destacando la forma ascendente en que las casas están dispuestas en la composición. La fotografía muestra una vista bastante menos elevada y una diferencia mucho más clara entre primer plano y plano de fondo. En la foto se exhibe la distancia entre los diferentes planos; en el cuadro, en cambio, el campanario se ve más arriba de las casas, no necesariamente más atrás: así también el cielo que aparece encajado en el contorno ofrecido por la accidentada línea de horizonte. Naturalmente, la fotografía de Loran también es obra de una mirada intencionada, no es lisa y llanamente registro de lo que está ahí delante. La intención del fotógrafo no era la de captar simplemente una vista de Gardanne: su voluntad era la de captar con su cámara, de la manera más exacta posible, el mismo motivo que unos treinta años atrás había estado frente a los ojos de Cézanne. Para alcanzarlo tenía como modelo a la pintura. Trató de adaptar en encuadre fotográfico al encuadre pictórico, precisar el punto de vista del pintor buscando «leer» el paisaje como Cézanne lo había hecho. De cualquier manera, lo que esta comparación revela es que ambos aparecen descalzados. Un mismo estímulo leído distintamente por diferentes intenciones.

En efecto, la peculiar organización espacial que se observa en sus cuadros debe su extrañeza a la suspensión que opera el pintor respecto de la aplicación de fórmulas: son ellas las que deben olvidarse, las que deben, en un momento dado, suspenderse. La organización de sus cuadros obedece a una lógica espacial que no existe a priori, una lógica que solo le pertenece al cuadro; la espacialidad del cuadro se forma en él, no se impone desde fuera, no es un molde que se aplica mecánicamente sobre la superficie. La insistencia de Cézanne respecto de la atención al modelo natural (que, por cierto, no es solo el paisaje, sino también una figura humana o un bodegón), se entiende en la medida en que es la experiencia misma frente al modelo la que determina la organización pictórica. La lógica del cuadro es resultado de una operación donde el pensamiento visual, ese pensamiento tramado con la percepción, se pone en obra. La lógica del cuadro traduce la lógica de la sensación.

\section{LA PERSPECTIVA DESAPRENDIDA}

La perspectiva renacentista y sus aplicaciones brindan un ejemplo de cómo una voluntad ordenadora se impone sobre la visualidad; la perspectiva era un prisma científico que se colocaba ante y sobre el mundo, y que ordenaba de manera coherente

5 Las fotografías de los motivos fueron tomadas entre 1927 y 1929, producto de la investigación de Erle Loran, artista recién graduado, quien viajó a Aix-en-Provence con el objeto de «descubrir» los motivos cezannianos. Afortunadamente para él, el paisaje de la provincia no había cambiado sustancialmente, lo que facilitó el hallazgo. 
(euclidiana) todo lo que entraba en los límites del cuadro. Imponía una óptica geométrica animada por una vocación de objetividad. En efecto, el anhelo de objetividad fue lo que movilizó la implementación del método de la perspectiva, sin embargo, no por ello puede afirmarse que esa objetividad haya sido alcanzada plenamente por dicho método. En efecto, podría pensarse, como lo plantea Herbert Read, que es precisamente la incapacidad del método perspéctico de alcanzar una objetividad más plena lo que quedó en evidencia con la investigación pictórica cezanniana ${ }^{6}$. La perspectiva que buscaba Cézanne en sus cuadros no obedecía a esas intenciones, lo cual queda en evidencia especialmente en sus naturalezas muertas, que exhiben puntos de vista disímiles, desafiando la coherencia del modelo perspéctico que se funda en la mantención de un punto de vista único. No era la perspectiva que la pintura occidental implementó como método a partir del siglo XV la que interesaba a Cézanne, sino, como señala Merleau-Ponty, una "perspectiva vivida» (subjetiva) que involucra percepciones del objeto mucho más complejas que las que puede proveer la perspectiva lineal geométrica o el lente fotográfico desde un punto de vista inamovible: en lugar de obedecer a unas normas geométricas el pintor obedece a una lógica de las sensaciones, a una organización que es intrínseca a ellas mismas. Cada cuadro, podría decirse, es la traducción de una particular experiencia, de una «perspectiva vivida» que tuvo lugar en el contacto con la naturaleza. Es el punto de vista de un sujeto particular, no el del sujeto implícito y abstracto de la perspectiva euclidiana. Y de ahí que no es una ausencia de perspectiva, ni de profundidad, lo que podemos apreciar en las pinturas de Cézanne: es una perspectiva otra, una perspectiva vivida pero traducida como experiencia al lenguaje de la pintura.

En el cuadro reproducido en la Figura 2 se puede observar nítidamente esta cuestión. La posición de los objetos representados pareciera estar desafiando las leyes de la física: la mesa no se ve -como sí sucede cuando se trabaja con la perspectiva «correcta» - perpendicular a lo que debiera ser el plano del suelo; más bien parece levantada de tal manera que las frutas, el canasto, el plato, etc., lucen como si pudieran «caerse». No coinciden tampoco sus bordes, ya que el lado izquierdo se ve notoriamente más bajo que el derecho. Por lo demás, tanto las frutas dispersas como el canasto, como el plato, en fin, están representadas de tal forma que parecen haber sido captadas desde puntos de vista distintos, de modo que el modelo del punto de fuga único se desmorona. La variedad en los ángulos de mirada que el cuadro muestra revela también de qué manera el cuerpo, y no solo el ojo, estaba involucrado en la aprehensión del motivo; el motivo es, de alguna manera, rodeado por el cuerpo.

6 «Antes de Cézanne, el artista, para resolver problemas (la representación de objetos en el espacio), hacía que intervinieran facultades extravisuales: podía ser su imaginación, que permitía transformar los objetos del mundo visible y crear un espacio ideal ocupado por formas ideales; o podía ser su intelecto que le permitía construir un mapa científico, una perspectiva en la que el objeto podía recibir una situación exacta. Pero un sistema de perspectiva no representa lo que ven los ojos con más exactitud de la que tendría una proyección Mercator como representación de lo que el mundo parece desde Sirio. Como el mapa, sirve de guía al intelecto: la perspectiva no nos procura vislumbre alguno de la realidad» (Read 14). 


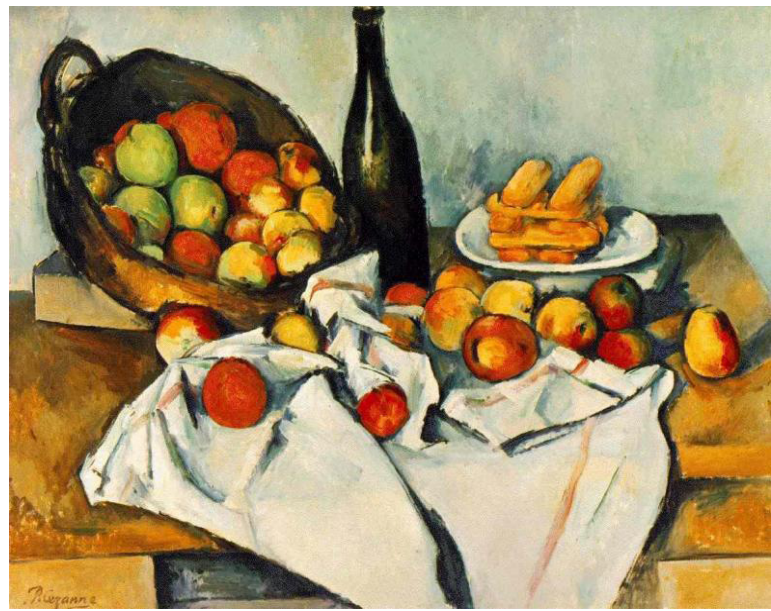

Figura 2. Paul Cézanne

La cesta de manzanas 1890-94

Óleo sobre tela

Art Institute of Chicago

Todo esto ocurre porque en su búsqueda de la armonía paralela Cézanne no se guía por la ley de gravedad, que justificaría que los objetos sobre una mesa inclinada se precipitaran al suelo, ni por las leyes de la perspectiva lineal, sino por una lógica del cuadro, por unas «leyes» que solo a la pintura, a esa pintura especifica, le corresponden, porque es producto de una experiencia particular. Tampoco la pintura deja ver un espacio "plano». No se ven superficies uniformes, ni formas recortadas (como sí las podemos ver, por ejemplo, en una pintura de Gauguin del mismo período). Las formas coloreadas revelan su modulación cromática y los mismos colores asumen el encargo de la variedad tonal que normalmente ejecuta el claroscuro.

No existe la línea, no existe el modelado; lo que hay solo son contrastes. El blanco y el negro no proveen esos contrastes; las sensaciones de color, sí. El modelado es el resultado de una perfecta combinación de colores:

El dibujo y el color no son distintos uno del otro, gradualmente cuando uno pinta, dibuja. Mientras más armoniosos son los colores, más preciso será el dibujo. La forma está en su plenitud cuando el color es más rico. El secreto del dibujo y el modelado yace en los contrastes y afinidades del color (Bernard, Sobre Cézanne 239).

Al declarar la supremacía del color, al insistir en que las armonías cromáticas, expresadas en afinidades y contrastes, eran las que articulaban el cuadro, Cézanne lograba sindicar el elemento decisivo de lo pictórico. Es en virtud del protagonismo del color que las formas se distorsionan y que las perspectivas se aplanan: el color determina la organización en su conjunto. Todo el aspecto que muestra un cuadro de Cézanne se debe a que coloca al color en el lugar de regente, desde donde se 
organiza todo o demás. Mal que mal, lo que pinta, repite una y otra vez, son sus sensaciones coloreadas:

Cuando el color tiene su riqueza, la forma tiene su plenitud.

Y quiero -me decía siguiendo sobre su puño cerrado el pasaje de las luces a las sombras- hacer con el color lo que se hace en blanco y negro con el esfumino (Denis 311).

El cromatismo para Cézanne era la transposición de valores de negro y blanco en equivalentes cromáticos, objetivo que lograba disponiendo con su pincelada una serie de manchas que se suceden por contrastes o por analogías. Si el arte en general se vale de las equivalencias, las equivalencias específicas con las que el pintor trabaja son las de color. Reemplaza la luz, la media tinta y la sombra por colores, que se organizan como pasajes y pantallas por obra de la modulación, es decir, del paso de un tono a otro.

Lo que ocurre en su pintura es el abandono de una fórmula (la de la perspectiva lineal) y no de los fines que esta perseguía: la representación de la profundidad. La fórmula en cuestión queda en desuso porque en lugar de contemplar la experiencia con la naturaleza, con el modelo, se sustentaba en fundamentos teóricos apriorísticos. Cézanne articula la generación de una trama de perspectivas que conjugan distintas sensaciones sobre las cosas del mundo y sus relaciones para articular un nuevo espacio. No son preceptos formales, paradigmas armónicos preestablecidos ni ningún tipo de fórmula probada los que operan en los cuadros de Cézanne. Antes bien, estos son fruto de un trabajo colaborativo: de ir y venir del paisaje al ojo, del ojo a la mente, de la mente a la tela. El ojo se educa en el contacto con lo visible, «la óptica, que se desarrolla en nosotros mediante el estudio, nos enseña a ver», le señalaba Cézanne a su joven amigo Émile Bernard. Por ello insistió hasta el fin de sus días en la importancia de observar los fenómenos, de interrogar a la naturaleza y dejarse interrogar por ella; tramarse con ella, concluyó, era la clave fundamental para alcanzar las metas pictóricas.

Si sus pinturas parecieran estar subrayando, en algunos casos, la literalidad del plano del cuadro, es porque Cézanne articulaba toda la superficie en virtud de la modulación del color. Si el resultado es la chatura y, como ocurre frecuentemente en los bodegones, la copresencia de perspectivas disímiles, no se da porque haya deliberadamente intentado fracturar el modelo perspéctico y poner fin a casi cinco siglos de ilusionismo tridimensional, sino porque creía posible traducir todo lo que el modelo de la naturaleza ofrece a equivalentes cromáticos, esto es, no lineales, no valóricos. No se trata de una negación de la atmósfera o la profundidad, muy por el contrario, se trata de la configuración de una trama producto de la modulación.

Acaso por eso es que afirmaba que era preciso mirar el mundo como lo hace un primitivo: no prejuiciadamente, ni desde una disposición ordenadora a priori, sino a partir de las propias sensaciones, desafiando la «actitud natural» y sus certezas. Lo que se representa no es el mundo ahí afuera ni el mundo de las ideas abstractas, tampoco el mundo subjetivo o interno del pintor sino las sensaciones obtenidas del 
enfrentamiento con la naturaleza. Desafía también Cézanne la «actitud académica», si por ello entendemos la regencia de ideas preconcebidas sobre la pintura. Recién ahí, cuando las certezas han sido relegadas, suspendidas, empieza a aparecer el modelo. La aparición del modelo es lo que precipita la representación; es aquello que se constituye al enfrentarse el pintor activamente con su motivo, aquello que antes no era nada. El modelo, entonces, no es un conjunto de datos ofrecidos por la naturaleza, tampoco un grupo de preceptos a aplicar. Motivo y modelo no son la misma cosa, a pesar de que el propio Cézanne usaba los términos indistintamente en su correspondencia. El motivo para Cézanne designa lo que el ojo y el cuerpo perciben; el modelo es algo que tiene lugar en una especie de intersticio entre lo que afuera se despliega, las sensaciones y la voluntad organizadora del artista.

\section{AL ENCUENTRO DEL MOTIVO}

Paul Cézanne arribó a París en 1861 siguiendo los pasos de su amigo de infancia Émile Zola, quien lo introdujo al círculo de sus amigos entre los que se encontraban algunos de los futuros pintores impresionistas. En París empezó a frecuentar la Académie Suisse ${ }^{7}$ de dibujo, lugar donde conoció al que sería su amigo y mentor, Camille Pisarro.

Años más tarde, animado por el temple antiacadémico del impresionismo y especialmente instigado por Pisarro, Cézanne comenzó, en la década del setenta, a ensayar con la pintura de paisajes siguiendo la modalidad del plein air. El consejo de Pisarro había sido, según afirmaba Lionello Venturi, «que se preocupara por la realidad exterior y no tanto por sus pasiones internas» (Venturi 52). El consejo estaba orientado a desincentivar las inclinaciones del joven Cézanne hacia el dramatismo barroco y la intensidad romántica. Gran admirador de la pintura del Tintoretto, Veronese, Rubens y Delacroix, Cézanne los tenía entonces por modelos recurrentes y su pintura era una extraña mezcla entre los estilos de aquellos maestros y las proyecciones colorísticas, matéricas y gestuales de su propio temple.

La sugerencia de Pisarro no fue acogida de inmediato. Cézanne tomó un tiempo en madurarla, no obstante, hacia el fin de la década se concentró en la realización de naturalezas muertas y en el estudio de los objetos, actividades que podrían considerarse como una preparación para la pronta observación del natural. Una vez que logró apaciguar las inclinaciones que lo dominaban en su juventud para enfrentarse, serenamente y sin urgencias, ante el paisaje, Cézanne abandonó de manera paulatina pero decisiva el ejercicio de una pintura nutrida de sueños y escenas imaginadas, para -gracias a la apertura otorgada por el contacto con el natural- empezar a concebirla y practicarla como un estudio de lo visible, como medio de organización

\footnotetext{
Cézanne empieza a asistir a esa academia luego de haber sido rechazado dos veces en su postulación a la Escuela de Bellas Artes. No se trataba, en realidad, de una institución de enseñanza, sino de un establecimiento en el cual se disponía de modelos vivos para la práctica del dibujo, pero donde no había correcciones ni exámenes.
} 
de la naturaleza. Con el tiempo llegó a una compenetración tan importante con el paisaje que se concibió a sí mismo como una suerte de conciencia de ese paisaje. Cézanne fue arribando a la convicción de que la única manera de lograr una verdadera realización pictórica era a partir de la observación del mundo, desde el natural. Se decidió a cambiar -podría decirse en principio- el modelo interior, tan acariciado por los románticos, por el modelo exterior defendido por los aliados del naturalismo, dentro de los que se contaban los propios impresionistas ${ }^{8}$.

\section{LA PROVINCIA DE LA PINTURA}

Su trabajo sobre el motivo se inició alrededor de 1871 en zonas de los alrededores de París como Louveciennes y Pontoise. En un inicio sus estudios aún exhibían, según Roger Fry, «el mismo énfasis dramático, igual exuberancia en el dibujo y en las violentas oposiciones de tonos. Domina el negro. Los rojos y ocres vienen a acentuar aún más la triste y pesada armonía» acaso porque el temple atribulado del artista dominaba el proceso y su «persona» se resistía a quedar en la sombra. Paulatinamente, frente al paisaje, Cézanne empezó a transitar desde sus imágenes internas al estudio de la naturaleza, y de esta suerte su pintura comenzó a desdramatizarse, a tornarse cada vez menos literaria y menos apasionada.

El cambio de dirección de la mirada -desde su mundo imaginario hacia el mundo sensible- fue absolutamente decisivo, pues determinó el curso que de ahí en adelante iba a tomar su carrera de pintor. La observación atenta del motivo predispuso la transformación de la actitud de Cézanne frente al modelo, a cualquier modelo, vivo o inanimado. A partir de sus nuevas observaciones sobre el motivo no solo se agrega la práctica de un género (el paisaje) antes inexplorado por él, sino que se modifica el modo en que aborda sus naturalezas muertas, género que venía practicando desde hacía tiempo. Como consecuencia de este enfrentamiento con la naturaleza, nace en el pintor una nueva forma de abordar el modelo, sea este un soleado paraje del mediodía, un grupo de manzanas sobre una mesa o la semblanza de Hortense Fiquet. Desde que se traslada a pintar frente a la naturaleza, la manera en que organiza la superficie y la forma en que modula el color y los tonos empiezan a ser otras. El negro abundante y la excesiva pastosidad del óleo que caracterizaban sus primeros trabajos emprenden la retirada, como también lo hacen esas visiones de sueños contaminadas de proyecciones anímicas que anteriormente se imponían sobre la tela.

$8 \quad$ Participó Cézanne de la primera y de la tercera exposición impresionista. En la célebre exposición de mayo de 1874, que tuvo lugar en el estudio del fotógrafo Nadar, se pudo apreciar dos de sus obras: Una moderna Olympia, en su segunda versión, y La casa del aborcado, realizado durante las temporadas que permaneció en Auvers como huésped del Dr. Gachet. En la tercera muestra participó con dieciséis obras, entre ellas una versión de sus Bañistas. En ambos eventos, el favor del público y de la crítica le fueron negados, incluso de una manera más cruenta que a sus colegas impresionistas.En reiteradas ocasiones hacia el fin de sus días expresó su admiración por la obra de Monet, Pissarro y Renoir. Su afirmación no corresponde a una negación del impresionismo, sino a la voluntad de darle perdurabilidad. 


\section{EL MOTIVO}

En el marco de los estudios que emprendió, el paisaje devino, para Cézanne, motivo. El paisaje no constituye por sí mismo el motivo tal como él lo entendía (es decir, modelo); un paisaje deviene motivo cuando se vuelve objeto de atención, una vez que la mirada ha ejercido su función aisladora que lo destaca de un horizonte informe, es decir, cuando se torna objeto de un acto de suspensión (epoché). Tenía muy claro que el motivo no era algo que apareciera simplemente, algo que solo se desplegara frente a él, por el contrario, este se hacía presente luego de serias cavilaciones.

En el paisaje y la naturaleza muerta, el pintor esperaba hallar una «ocasión» pictórica, como bien lo expresó más tarde Maurice Denis, una oportunidad para establecer una traducción de la naturaleza al lenguaje de la pintura. Reconocer el motivo como ocasión pictórica le permite instalarse «sobre él» (sur le motif); ejercer sobre él una clase de control. Esta conciencia del motivo / modelo es la que da inicio, la que pone en marcha la investigación pictórica de Cézanne. Hasta entonces podía acaso hablarse de experimentación; de ahí en adelante, me parece, puede hablarse de investigación sostenida y metódica.

El énfasis que pone en el análisis del motivo coincidió con el retiro definitivo del maestro a Aix en Provence, a partir de 1890. Este hombre huraño, que no se interesaba por la captación de lo transitorio, lo fugitivo y lo contingente, que regañaba contra la modernización, que buscaba la fórmula para darle solidez al método impresionista, encontró, al retornar a su natal Provenza, el estímulo necesario para aguzar su conciencia pictórica. Allí se le revela, de algún modo, que el arte debe aspirar a ser «una armonía paralela a la naturaleza», esto es, que el arte debe constituir un cosmos separado, distinto pero equivalente; que la tarea del pintor no es replicar, sino traducir. Del estudio penetrante del motivo, de su contacto con las cosas mismas, va derivando la necesidad de cultivar una visión lógica donde colaboren el ojo y la mente, donde la sensación se comprometa con el entendimiento en una relación dialéctica. Dijo Cézanne, de acuerdo a la memoria de Émile Bernard:

Dentro del pintor hay dos cosas: el ojo y el cerebro. Ellos deben servirse el uno al otro. El artista debe trabajar desarrollándolos mutuamente: el ojo gracias a la visión de la naturaleza y el cerebro por la lógica de las sensaciones organizadas, la cual es provista por los medios de expresión (Bernard, Sobre Cézanne 38).

Si admitimos la expresión de los recuerdos proporcionados por Bernard -que se aleja probablemente de la forma menos elocuente en que el viejo pintor expresaba sus ideas- encontramos allí una lucidez que de ningún modo puede extrañarnos en un investigador activo como era Cézanne. El pintor debe poner a actuar el ojo pero también la mente; o el ojo debe ponerse al servicio de la mente y viceversa; entre ambos protagonizan un diálogo productivo, ambos son agentes de la misma ope- 


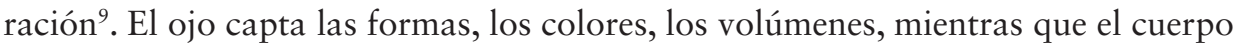
experimenta las sensaciones y la mente las organiza como equivalentes pictóricos. La lógica del cuadro, es decir, de eso que no pertenece al mundo y que es independiente del autor, es una lógica pictórica que proviene de las sensaciones visuales que el estar en el mundo origina, pero cuyo funcionamiento, cuya operatividad, depende del control sobre los medios. La propia obra cezanniana se encarga de exhibir esa colaboración.

\section{LA LÓGICA DE LAS SENSACIONES}

\section{La sensation}

Llegar a formular suficientemente bien las sensaciones que experimentamos al contacto con la bella naturaleza -hombre, mujer, naturaleza muerta-, y que las circunstancias le sean favorables; eso es lo que yo le deseo a todo simpatizante del arte.

Cézanne a Louis Leydet, enero de 1905

Sensation era un término que se volvió frecuente en el contexto del impresionismo. En 1874, el crítico naturalista Jules Castagnary afirmó, con ocasión de la muestra del Grupo de Batignolles en el estudio de Nadar, que: «Son impresionistas en el sentido de que plasman no el paisaje, sino la sensación producida por el paisaje» (Solana 15). Se desprende de lo anterior que Castagnary adjudicaba a la sensación una naturaleza más bien subjetiva, ya que su utilización, es decir, el hecho de que los pintores referidos no representaran lo visto sino su respuesta frente al paisaje, determinaba su lejanía de las fórmulas «objetivas» que buscan representar lo visible de modo neutral.

Al comentar la fase en que Monet y Renoir, pintando la Grenouillère, alcanzaron la técnica de la pincelada en forma de coma que les permitía no solo captar las formas, sino también la atmósfera y la luz, el historiador del impresionismo John Rewald señaló: «La naturaleza cesaba de ser un objeto susceptible de interpretación como lo fuera para los pintores de Barbizon; se convertía ahora en la fuente directa de sensaciones puras y nada podía reproducir mejor esas sensaciones que la nueva técnica que en lugar de insistir en los detalles, retenía la impresión general en toda la riqueza de color y de vida» (Rewald 242). De cualquier modo, para los impresionistas la sensación debió ser algo prácticamente igual a la impresión. Impresión que surge de un estímulo visual pero que siempre es personal, puesto que si bien es cierto los

\footnotetext{
«Como siempre, Cézanne realiza la operación simultáneamente a dos niveles, el de la abstracción de la forma y el de la fisicidad del color, del cerebro y del ojo, del museo y la naturaleza, sin renunciar nunca a uno de los dos términos del binomio, sino trabajando obstinadamente en vistas a su integración orgánica, a una lógica de las impresiones colorísticas organizadas. [...] Para Cézanne el ojo y el cerebro no se consideran como categorías abstractas sino como funciones inherentes a la estructura biopsíquica» (Menna 27).
} 
impresionistas mantuvieron la observación del modelo, del paisaje o lo que fuera, estaba más que claro que no pretendían mostrar una visión objetiva de él, aunque sus posteriores detractores los acusaran de «no tener más que ojo».

Pareciera ser, entonces, que el término sensación porta una ambigüedad, ya que designa al mismo tiempo una experiencia subjetiva y una puramente perceptual. Indica una experiencia tramada con la percepción pero que involucra también aquello que lo percibido provoca como efecto. El dato sensible por sí solo no constituye la sensación. Eso era algo que los impresionistas intuían, pero que Cézanne desarrolló más conscientemente para configurarlo como el sustento de todo trabajo. «Yo sigo trabajando con dificultad, pero en fin, algo se saca. Es importante creo yo. Las sensaciones constituyen el fondo de mi asunto» (Cézanne 373, el énfasis es mío). La ambigüedad presente en la palabra sensación favorecía las necesidades expresivas de Cézanne. Justamente, porque ello le permitía insistir en el indisociable vínculo, o, mejor dicho, en la trama indisoluble entre lo visto y su aprehensión mental. Cuando Cézanne refiere a "su sensación» -que no es lo mismo que una sensación cualquiera, sino una sensación propiamente pictórica- está hablando del «fondo de su asunto». Un mes antes de su muerte le escribe a su hijo Paul:

En fin te diré que, como pintor, me siento más lúcido delante de la naturaleza; pero que, en casa, la realización de mis sensaciones sigue siendo muy penosa. No consigo alcanzar la intensidad que se desarrolla ante mis sentidos; no tengo esa magnífica riqueza de coloración que late en la naturaleza. Aquí a orillas del río, los motivos se multiplican; el mismo motivo visto bajo un ángulo distinto ofrece un tema de estudio de poderosísimo interés y tan variado que creo que podría estar ocupado durante meses sin cambiar de sitio, simplemente inclinándome unas veces hacia la derecha y otras más a la izquierda (Cézanne 343).

La carta subraya una cuestión que Cézanne viene insistentemente sugiriendo: que las sensaciones fuertes e intensas, esas que han de ser traducidas al lienzo, solo pueden experimentarse al contacto con la naturaleza. El trabajo de taller, lejos del motivo, no admite la sensación, antes bien, provoca su evanescencia. Es la atención al motivo lo que garantiza su fijación. Al leer la naturaleza como Cézanne lo hacía, ya en el mismo acto que, por cierto, no es instantáneo, interviene la sensación (sensation). La conjunción entre el ojo y el espíritu (esprit) se produce en la mirada que opera sobre el motivo y no en un acto separado ${ }^{10}$. Efectivamente, no transa el pintor respecto de esa unidad, de esa comunión imperiosa que él capta en su propio encuentro con el paisaje. En una de sus últimas cartas le insiste a su hijo Paul: «Tengo, pues, que pintar del natural. Los esbozos, los lienzos, si los hiciera, no

10 Como bien ha expresado Merleau-Ponty: «Cézanne no creyó tener que escoger entre sensación y pensamiento, ni tampoco entre caos y orden. No ha querido separar las cosas fijas que aparecen ante nuestra mirada y su manera fugaz de mostrársenos, ha querido pintar la materia dándose forma a sí misma, el orden que nace de una generación espontánea. No ha marcado ninguna ruptura entre «los sentidos» y "la inteligencia», sino entre el orden espontáneo de las cosas percibidas y el orden humano de las ideas y las ciencias» (Merleau-Ponty Sentido y sinsentido 39). 
serán más que construcciones a partir de [la naturaleza], basadas en los medios, las sensaciones y los desarrollos sugeridos por el modelo; pero siempre estoy diciendo lo mismo» (Cézanne 411).

Como ocurre con algunos de los conceptos clave que Cézanne utiliza, es difícil afinar una significación unívoca. Sin embargo, es posible especular que su sentido no estaba restringido a lo meramente óptico o a lo que en la época se denominaba «retiniano», para aludir al carácter que supuestamente habría adquirido la pintura desde Courbet. La sensación, se puede deducir, no es algo pasivo, sino que involucra un proceso complejo de interacciones entre lo percibido, lo sentido y lo organizado y, precisamente por ello, hablaba Cézanne de la necesidad de leer la naturaleza, de penetrar la trama de su complejidad, porque es esa penetración la que genera la sensación. Nada está simplemente ahí delante para ser meramente captado. La sensación no está afuera, en el fenómeno, aunque este la provoca, sino que es algo que, de alguna manera, toca al artista, que lo conmueve porque forma parte tanto de él como de lo que está observando: es, de alguna manera, un «entre». Hablando de Cézanne acota Deleuze:

La sensación es lo contrario de lo fácil y lo acabado, del cliché, pero también de lo «sensacional», de lo espontáneo... etc. La sensación tiene una cara vuelta hacia el sujeto (el sistema nervioso, el movimiento vital, el «instinto», el «temperamento», todo un vocabulario común al naturalismo y a Cézanne), y una cara vuelta hacia el objeto («el hecho», el lugar, el acontecimiento). O, más bien, no tiene del todo dos caras, es las dos cosas indisolublemente, es ser-en-el-mundo, como dicen los fenomenólogos: a la vez devengo en la sensación y algo ocurre por la sensación, lo uno por lo otro, lo uno en lo otro (Deleuze 41).

La sensación tiene dos caras. Dicho de otra forma: opera entre la naturaleza y su aprehensión. Para Cézanne, la sensación representa una integración entre lo sintiente y lo sentido. El motivo, el paisaje, la vista, no son suficientes para el artista, sin embargo, son imprescindibles para generar la sensación. Atento al motivo, se niega Cézanne a todo lo que pudiera distraerlo de la pintura: no quiere "comprometer su pequeña sensación, como decía él sirviéndose de los estetas de su juventud: evita a la vez el trompe l'oeil y la literatura» (la reproducción de las apariencias y la narratividad $)^{11}$. Una cuestión que es importante mantener de relieve es que la sensación, mejor dicho, la certeza respecto del rol de la sensación en su pintura, es lo que mantiene al pintor atento al modelo.

Cézanne repitió, una y otra vez, que aspiraba a pintar sus propias sensaciones respecto de la naturaleza. Se podría pensar, en primera instancia, que al pintar sus sensaciones lo que hacía era suplantar el modelo interior basado en la mirada del ojo cíclope del alma (el modelo romántico) por un modelo objetivo, articulado a

11 «El artista debe despreciar todo juicio que no esté basado en una inteligente observación del asunto. Debe precaverse contra el espíritu literario, que tan a menudo provoca que el pintor se aparte de su verdadero camino -el estudio concreto de la naturaleza- para perderse en largas e intangibles especulaciones», dijo a Bernard (Cézanne 373). 
partir de lo visto. No obstante, lo que en realidad hacía era poner a ambos en colaboración, solo que la mente o el espíritu no proyectaba emociones desbordadas independientes de las percepciones sensibles, sino una voluntad de organizarlas en un lenguaje pictórico. La sensación es la clave, el punto de equilibrio donde colaboran las percepciones ópticas y el control de los medios pictóricos. Contra la confusión y la contingencia, la estructura; frente a la estructura rígida, la naturaleza. La sensación garantiza su articulación.

\section{LA REALIZACIÓN (LA RÉALISATION) Y LOS MEDIOS DE EXPRESIÓN}

Me habla en su carta de mi realización en el terreno del arte. Yo creo que cada día me acerco más a ella, si bien con gran esfuerzo. Pues si la sensación fuerte de la naturaleza-bastante viva en mí, por cierto- es la base necesaria de toda concepción artística, sobre la que descansa además la grandeza y la belleza de la obra futura, el conocimiento de los medios para expresar nuestra emoción no es menos esencial, y no se adquiere sino mediante una larga experiencia.

Cézanne a Louis Aurenche, enero de 1904

La sensación tiene lugar cuando el pintor se encuentra con el motivo, pero la sensación es efímera, huidiza: solo cobra forma y se materializa cuando la voluntad del artista traduce esas sensaciones a la tela con los medios pictóricos. La realización corresponde a un momento del proceso pictórico donde el control de los medios expresivos es primordial. Es la fijación de la sensación. Solo puede alcanzarse cuando estos medios, con los que la sensación va a traducirse y a fijarse, están plenamente dominados por el artista, es decir, cuando el pintor ha logrado organizarlos metódicamente. La palabra realización tiene en francés, como en español, dos acepciones fuertes. Por una parte se entiende como construcción, producción, hacer que algo llegue a tener existencia (pasar del estado de la concepción al de la ejecución), en otras palabras «hacer real», y, por otra, también se comprende como logro, cumplimiento, como alcance de una meta. Ambas son pertinentes cuando se piensa en la pintura y en las afirmaciones reiteradas del pintor. En este punto es adecuado citar de nuevo la frase que estimuló esta investigación: "La lectura del modelo y su realización son a veces cosas que tardan en llegar».

Eso que tarda en llegar, que es la lectura, pero sobre todo, la realización, aparece en el horizonte como una meta, como un objetivo que es necesario alcanzar, como el fin último que moviliza toda la investigación pictórica. Cézanne tuvo dudas: nunca estuvo seguro de haber alcanzado ese logro; por eso mismo su investigación nunca se detuvo. No obstante, si el cumplimiento del logro ha de ser juzgado por 
la consistencia alcanzada por lo que él mismo llamaba «la materialización» de sus sensaciones, sus pinturas exponen una consecución que se expresa en la solidez de la trama pictórica, en el sólido tejido que ofrece como realización. Quiero decir: si el pintor expresaba sus dudas, sus pinturas las han disipado. La trama, tan estrecha y consistente, de los cuadros cezannianos, se revela como la traducción visual de la realización, del equilibrio logrado. La superficie finadamente tramada de cada cuadro se exhibe como manifestación concreta de la colaboración del ojo y la mente en la concepción de la pintura. Una concepción que antecede a la realización pero que solo se materializa al realizarse pictóricamente. El cuadro posee esa consistencia que suelen tener los tapices: es un tejido compacto, nada se escapa; cada centímetro cuadrado tiene su lugar en la superficie, cada elemento, cada imbricación entre ellos, es prueba de interdependencia y solidaridad.

La solidez de la trama se logra más que por una composición bien planeada, por la organización de los colores a través de lo que Cézanne llamaba modulación. Modulación es un concepto musical que designa a los pasajes (passages) entre diferentes tonalidades. Cézanne consideró que «modular», que era un verbo relativo a la música, era mucho más adecuado para comunicar su método que «modelar», que es un verbo que más bien señala un procedimiento escultórico. El empleo de la modulación era algo acorde con el objetivo que quería alcanzar: la armonía. Según Bernard, el pintor habría afirmado: «Leer la naturaleza es como verla a través de un velo, en términos de una interpretación en segmentos de color que se siguen el uno al otro de acuerdo a la ley de la armonía» (Bernard, Sobre Cézanne 38).

El plano de color equivalía a los sonidos o las notas que al organizarse conformaban el todo armónico. El cromatismo para Cézanne era la transposición de valores del claroscuro en negro y blanco a equivalentes cromáticos, objetivo que lograba disponiendo con su pincelada una serie de manchas que se suceden por contrastes o por analogías. Si el arte en general se vale de las equivalencias, las equivalencias específicas con las que el pintor trabaja son las de color. Reemplaza la luz, la media tinta y la sombra por colores, que se organizan como pasajes y pantallas. De la modulación depende la exaltación de cada color; la modulación es, en definitiva, la que configura la trama pictórica: «Toda la tela es un tapiz en que cada color 'canta' separadamente y sin embargo, funde su sonoridad en el conjunto", decía Maurice Denis subrayando la metáfora musical que era en sí misma la noción de modulación, que en música significa pasar de un tono a otro. 


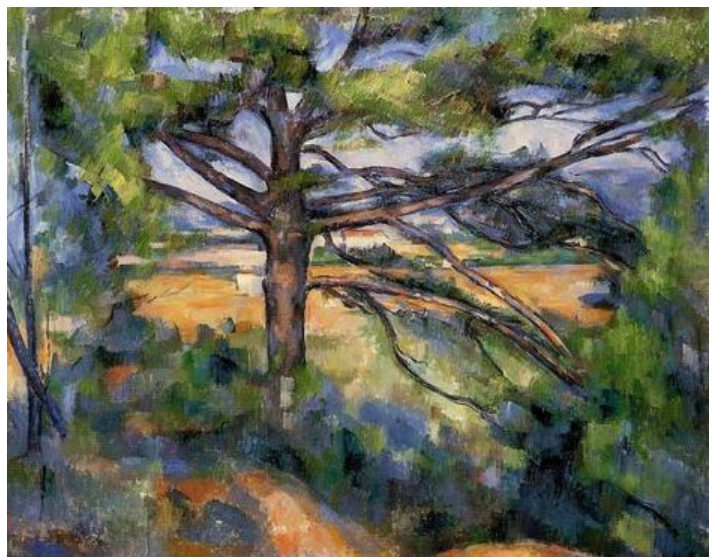

Figura 3. Paul Cézanne

Gran pino y tierra roja, 1890

Óleo sobre tela, 72 × $91 \mathrm{~cm}$

Museo The Hermitage, Leningrado

La Figura 3 muestra cómo opera el método de la modulación. Los distintos tonos verdes y azulados se organizan meticulosa pero sensiblemente por medio de las pinceladas, generando una suerte de mosaico. Van pasando de un tono a otro por obra de una cuidada modulación que no responde solo a un objetivo estético decorativo, sino a la voluntad de traducir los pasajes y pantallas que el pintor observa en la misma naturaleza que tiene en frente (y que la pintura tradicional traducía por medio del claroscuro). La sustitución del claroscuro por el color es obra del modulado, ya que, si aplicara un modelado, solo estaría sugiriendo ilusionistamente los volúmenes y no la atmósfera, el aire que rodea los objetos.

La realización persigue la consistencia, y esa consistencia se traduce en la solidez alcanzada por unos cuadros que se revelan como estructuras indisolubles. A ello también aludió Denis al dar cuenta de la sólida e impenetrable construcción cezanniana: «El aspecto característico de los cuadros de Cézanne nace de esta yuxtaposición, de este mosaico de tonos separados y levemente fundidos entre sí» (Denis 312). Esta trama, este tejido impenetrable, es la expresión correlativa del balance que infatigablemente buscaba el pintor, la meta de realizar ese que era su mayor objetivo: una armonía paralela a la naturaleza.

Para alcanzar la realización, el conocimiento y el dominio de los medios de expresión es tan fundamental como la lectura de la naturaleza, o, más precisamente, uno y otra están imbricados, nutriéndose el uno a la otra y viceversa. Es fundamental para Cézanne comprender que existe una especificidad de la pintura y que ella es de orden material. Es por eso que le expresa a Bernard:

El literato se expresa con abstracciones, mientras que el pintor concreta, por medio del dibujo y del color, sus sensaciones y sus percepciones. Nunca se es demasiado escrupuloso ni demasiado sincero ni demasiado sumiso para con la naturaleza; pero se 
es más o menos dueño del modelo y, sobre todo, de los medios de expresión. Penetrar lo que se tiene ante los ojos y perseverar en expresarse uno de la manera más lógica posible (Cézanne 375).

El control de los medios expresivos obedece en buena parte a la educación del ojo en la naturaleza, pero también depende de la experiencia con el propio arte; de otra manera Cézanne no se habría pensado a sí mismo como un continuador. No encarnó ningún tipo de programa orientado a desmantelar o abolir la tradición; por el contrario, creyó indefectiblemente que como artista no hacía más que recoger una hebra dejada por otros: «en mi pensamiento, no suplantamos al pasado, lo único que hacemos es añadir un nuevo eslabón» (Cézanne 389), expresó en una carta a Roger Marx. Sí alguna vez se definió como un «primitivo de un nuevo arte», no era para cambiar el curso de la historia de la pintura radicalmente, sino para afianzar sus fundamentos, indagando en sus procedimientos primarios, en su base. La realización no puede darse en las antípodas, sino en el equilibrio de intenciones, en una especie de cuerda floja. Su insistencia majadera sobre la importancia que tenía para él, como pintor, partir desde la naturaleza, no invalidó nunca su aprecio por el arte de los antiguos maestros (los que, suponía, habían obrado del mismo modo). Lo que intentaba transmitir a sus jóvenes amigos y seguidores era la necesidad de complementar ambos saberes (el del arte y el de la naturaleza). Esto se expresó finalmente en lo que él llamaba «el conocimiento de los medios de expresión». La naturaleza debe convertirse en la gran maestra no porque sea superior al hombre o a su obra, sino porque provee una experiencia complementaria, necesaria para calibrar al artista. Al pintor Charles Camoin le aconsejaba:

Id al Louvre. Pero tras haber visto a los grandes maestros que ahí descansan, es preciso apresurarse a salir de allí y vivificar en uno mismo, al contacto con la naturaleza, los instintos, las sensaciones artísticas que residen en nosotros (Cézanne 377).

Primero el Louvre, luego la naturaleza. A la naturaleza había que enfrentarla teniendo un manejo, un conocimiento de los medios pictóricos, una cuestión que se da en el entrenamiento de la visión: ver la naturaleza, ver también lo que otros antes que él han hecho por traducirla. Ni muy sumiso ni muy receloso, el punto medio es algo que se puede alcanzar siempre y cuando el pintor posea el control para dominar los medios con los que traduce su modelo a la tela. Lo que aconsejaba a los jóvenes artistas provenía de su propia experiencia, de su propio camino a la realización y del camino a la realización recorrido por otros antes que él. Sabía bien Cézanne que al motivo no se arriba inocentemente; ver es una experiencia nutrida de experiencias previas y paralelas, no solo del mundo, también del arte y sus desafíos. La realización necesitaba, más que nada, de esa experiencia.

La realización, eso que suele «tardar en llegar» y que Cézanne nunca estuvo seguro de haber alcanzado, sería precisamente la unidad entre conciencia subjetiva y conciencia objetiva, entre tela y paisaje, entre pintura y naturaleza. Al margen de 
esa unidad, lo paralelo, el equivalente que Cézanne buscaba, no puede ni siquiera ser pensado. En ese sentido, el esfuerzo cezanniano se encamina directamente hacia una plena autonomía de la forma artística, como se venía esbozando desde los albores de la modernidad. Tal vez podría pensarse en la realización cezanniana como en la realización de la pintura misma: una pintura existiendo con autonomía, pero una autonomía que no significa independencia o abandono del mundo, sino mundo (o sensación sobre el mundo) expresado con los medios propios de la pintura.

El uso de la palabra realización (réalisation) induce a pensar también en la intención de otorgar al cuadro, o a los elementos que lo componen, un estatuto de realidad. En este caso, realización es producción de una existencia totalmente nueva, algo que se añade al mundo. Una verdadera poiesis. Realizar significa instituir algo que antes no existía por cuenta propia, hacer realidad; por lo tanto, significa renunciar a la mímesis imitativa (valga la redundancia). Darle consistencia, otorgarle realidad a la sensación en algo tan concreto como una articulación de colores organizados sobre una tela. La equivalencia con la naturaleza no puede darse (no se puede alcanzar la realización) si lo producido no es más que un simulacro, un símil. Para que la pintura constituya verdaderamente «una armonía paralela» con la naturaleza no puede conformarse con su imitación, sino que debe constituir ella misma una realidad plena. Y eso, para Cézanne, exigía de parte del artista un respeto soberano por el modelo: la convicción absoluta de su condición irrenunciable.

\section{EL MODELO}

El modelo, vuelvo a insistir, puede ser comprendido como aquello que pone en marcha el acto mismo de pintar, aquello que articula la relación entre lo visto y lo pintado. En el caso de Cézanne es, podría decirse plenamente, la sensación. «Lo pintado es la sensación», dice Deleuze, pero la sensación no es solo lo visto ni solo lo pintado. Es lo que el pintor busca traducir. No es algo cuya existencia anteceda a la obra, ni como objeto del mundo ni como precepto teórico. Pero tampoco el modelo es la obra, el cuadro; el modelo es lo ausente que se trae a presencia. Recurriendo al modelo el pintor no reproduce al mundo, sino que ofrece una mirada sobre él, mirada que a su vez se transfigura en mundo otro, mundo pintado. Ardua tarea la que Cézanne se impuso. El cumplimiento de tal desafío es para Cézanne la realización, eso que nunca estuvo seguro de haber logrado. No es de extrañar que a solo un mes de su muerte se preguntara:

¿Alcanzaré la meta tan buscada y ansiada durante tanto tiempo? Estudio siempre del natural y me parece hacer lentos progresos. Así lo deseo; pero mientras no la haya alcanzado, subsiste en mí una vaga sensación de malestar, que solo podrá desaparecer cuando haya llegado a buen puerto... (Carta a Émile Bernard, septiembre 1906).

El motivo es el referente externo que gatilla la sensación. Una vez configurada la sensación, recién ahí aparece el modelo: aquello que el pintor se propone pintar. 
El modelo es lo que articula la relación entre lo visto y lo pintado. No es algo cuya existencia anteceda a la obra. La naturaleza existe, existían los objetos: la montaña de Saint Victoire, las canteras de Bibemus, el jardinero Vallier, árboles, manzanas, jarrones posaban, estaban allí antes, pero la sensación fue lo que los hizo devenir modelos. La sensación media entre la naturaleza y el cuadro y aquí se puede decir también que la sensación es la que configura el modelo, o tal vez no sea arriesgado afirmarlo: la sensación es, para Cézanne, el modelo.

\section{REFERENCIAS}

Ashton, Dore. Una fábula del arte moderno. Madrid: Fondo de Cultura Turner, 2001. Medio impreso.

Bernard, Émile. «Paul Cézanne. 1904-1980». Sobre Cézanne: conversaciones y testimonios. Ed. Michael Doran. Barcelona: Gustavo Gili, 1980. 55-70. Medio impreso.

---. «Recuerdos sobre Paul Cézanne». Sobre Cézanne: conversaciones y testimonios. Ed. Michael Doran. Barcelona: Gustavo Gili, 1980. Medio impreso.

---. «Una conversación con Paul Cézanne. 1921-1980». Sobre Cézanne: conversaciones y testimonios. Ed. Michael Doran. Barcelona: Gustavo Gili, 1980.214-17. Medio impreso.

Bozal, Valeriano. Los primeros diez años: 1900-1910, los orígenes del arte contemporáneo. Madrid: Visor, 1993. Medio impreso.

Bryson, Norman. Visión y pintura: la lógica de la mirada. Madrid: Alianza, 1991. Medio impreso.

Cézanne, Paul. Correspondance, recueillie, annotée et preface par John Rewald. París: Bernard Grasset Editeur, 1937. Medio impreso.

---. Correspondencia. Ed. John Rewald. Madrid: Visor, 1991. Medio impreso.

Denis, Maurice. Teorías. Buenos Aires: Ateneo, 1944. Medio impreso.

Deleuze, Gilles. Bacon o la lógica de la sensación. Madrid: Arena, 2000. Medio impreso.

Doran, Michael. Sobre Cézanne: conversaciones y testimonios. Barcelona: Gustavo Gili, 1980. Medio impreso.

D’Ors, Eugenio. Cézanne. Barcelona: El acantilado, 1999. Medio impreso.

Eisenman, Stephen. Historia crítica del arte del siglo XIX. Madrid: Akal, 2001. Medio impreso.

Fry, Roger. Cézanne A study of his development. Estados Unidos: Kessinger Publishing, 2004. Medio impreso.

Gasquet, Joachim. Cézanne. Lo que vi, lo que me dijo. Madrid: Gadir, 2009. Medio impreso.

Greenberg, Clement. Arte y cultura. Buenos Aires: Paidós, 2002. Medio impreso.

Harrison, Charles y Paul J. Wood (eds.). Art in Theory 1815-1900: an Anthology of changing ideas. Oxford: Blackwell Publishing, 1998. Medio impreso.

Husserl, Edmund. Ideas relativas a una fenomenología pura y una filosofía fenomenológica. México: Fondo Cultura Económica, 1993. Medio impreso. 
Loran, Erle. Cézanne's Composition. Analysis of his form with diagrams and photographs of his motifs. Berkeley: University of California Press, 1985. Medio impreso.

Mallarmé, Stepháne. «Los impresionistas y Edouard Manet». Ed. Solana, Guiller. El impresionismo: la visión original. Antología de la crítica de arte (1867-1895). 95-109. Medio impreso.

Menna, Filiberto. La opción analítica del arte moderno. Barcelona: Gustavo Gili, 1977. Medio impreso.

Merleau-Ponty, Maurice. Sentido y sinsentido. Trad. Narcís Comadira. Barcelona: Península, 2000. Medio impreso.

---. Fenomenología de la percepción. Trad. Jem Cavanes. Barcelona: Península, 1997. Medio impreso.

---. El ojo y el espíritu. Trad. Jorge Romero Brest. Barcelona: Paidós, 1986. Medio impreso.

---. Lo visible y lo invisible. Trad. José Escudé. Barcelona: Seix Barral, 1970. Medio impreso.

Reed, Christopher (ed). A Roger Fry Reader. Chicago: University of Chicago Press, 1996. Medio impreso.

Reef, Theodore. "Cézanne and Poussin». Journal of Warburg and Courtauld Institute $23 \mathrm{~N}^{\circ} \frac{1}{1 / 2}$ (1960). 150-74. Medio impreso.

Rewald, John. Historia del impresionismo. Tomo 2. Barcelona: Seix Barral, 1972. Medio impreso.

---. Cézanne, su vida, su obra, su amistad con Zola. Buenos Aires: Quetzal, 1955. Medio impreso.

Rilke, Reiner María. Cartas sobre Cézanne. Trad. Nicanor Ancoechea. Buenos Aires: Paidós Estética, 2000. Medio impreso.

Shapiro, Meyer. El arte moderno. Madrid: Alianza Forma, 1988. Medio impreso.

Shiff, Richard. Cézanne y el fin del impresionismo: estudio de la teoría, la técnica y la valoración crítica del arte moderno. Madrid: Visor, 2002. Medio impreso.

Solana, Guiller (ed.). El impresionismo: la visión original. Antología de la crítica de arte (1867-1895). Madrid: Siruela, 1997. Medio impreso.

Venturi, Lionello. Cuatro pasos hacia el arte moderno. Buenos Aires: Nueva Visión, 1960. Medio impreso. 